\title{
Treatment of Copper-Contained Jewellery Wastewater by Precipitation and Adsorption Using Rice Husk Charcoal
}

\author{
Maria A. Tuas ${ }^{1}$, Ali Masduqi ${ }^{2 *}$ \\ 1 Timor University, Jalan El Tari-Km 09, Sasi, Kefamenanu, East Nusa Tenggara 85613, Indonesia \\ 2 Dept. of Environmental Engineering, Faculty of Civil, Environmental and Geo Engineering, Institut Teknologi \\ Sepuluh Nopember, Jalan Raya ITS, Kampus ITS Sukolilo, Surabaya 60111, Indonesia \\ * Corresponding author's e-mail: angeltuas03@gmail.com
}

\begin{abstract}
The wastewater from the jewellery industry generally contains a large amount of metal. Metal removal can be done with many techniques, including precipitation and adsorption. Precipitation is done to convert the metal content from the dissolved phase to a solid that is easily precipitated. Generally, precipitation is unable to separate one hundred percent of metal content, so further processing is needed, i.e. adsorption. This research was done by using rice husk which is an agricultural waste in Indonesia. The rice husk is burnt to charcoal, then activated with acid. A SEM-EDX analysis was conducted to obtain a surface description of rice husk charcoal before and after use in the adsorption process. The results showed that the copper content in the jewellery wastewater can be adsorbed with a 40-50 mesh rice husk charcoal and the adsorption process follows the Freundlich isotherm model with R2 value of 0.9625 .
\end{abstract}

Keywords: adsorption, copper, jewelry industry, rice husk charcoal.

\section{INTRODUCTION}

The wastewater from various industries such as jewellery industry, iron ore processing, rust cleaning, mining, battery industry, galvanized, paint, and ink are found to contain heavy metals. In order to remove the heavy metal content in wastewater, methods such as adsorption, chemical precipitation, membrane filtration, reverse osmosis, ion exchange, nanotechnology treatments, electrochemical and advanced oxidation processes have been used [Lata and Samadder, 2014; Azimi et al., 2017]. Adsorption proved economical and efficient to remove heavy metals such as cadmium, lead, chromium, copper, nick$\mathrm{el}$, and zinc from contaminated waters [Karniba et al., 2014]. According to [Asuquo et al., 2017], the heavy metal adsorption process with activated carbon is highly efficient at the surface area of the adsorbent ranging from 500 to $1.500 \mathrm{~m}^{2} / \mathrm{g}$.

Alternatively, rice husk ash can be used as an adsorbent because of the presence of carboxyl and hydroxyl functional groups [Mullick et al., 2017; Alexander et al., 2017]. Other contents are carbonyl, phenolic, carboxyl, hydroxyl, imidazole, sulfide, amino, phosphate, sulfate, and amide [Lata and Samadder, 2014]. The ability of the adsorbent to form chemical bonds with metal ions into metal complexes or chelates is affected by the functional groups. In this paper, we discussed the results of the study of chemical precipitation and adsorption of copper in wastewater by rice husk ash as adsorbent. In this study, chemical precipitation was carried out as preliminary treatment before being adsorbed. The wastewater samples were taken from the jewellery industry waste in Surabaya, Indonesia and the rice husks were obtained from agricultural waste in East Java, Indonesia. Hopefully, with the application of the results of this research, the solutions to two waste problems, namely jewellery industry waste and agricultural waste will be obtained. The agricultural wastes were utilized as adsorbent by [Noor et al., 2007] and [Rahman et al., 2012]. 
Several studies were conducted to remove the heavy metal content with rice husk, by [Alexander et al., 2017; El-Moselhy et al., 2017; Hanum et al., 2017; Hsu et al., 2009; Ye et al., 2012]. Rice husk was washed, dried with oven at $70^{\circ} \mathrm{C}$ for 24 hours and then homogenized to uniform particle size [El-Moselhy et al., 2017]. This rice husk is used to remove cadmium and copper. The optimum conditions were obtained at $\mathrm{pH} 6$, the adsorbent mass $0.2 \mathrm{~g}$, contact time 120 minutes, initial concentration $10 \mathrm{mg} / \mathrm{L}$, and temperature $30^{\circ} \mathrm{C}$. [Hanum et al., 2017] used carbonized rice husk at $500^{\circ} \mathrm{C}$ for 150 minutes, immersed in $\mathrm{HCl}$ $5 \%$ with carbon-acid ratio $1: 10(\mathrm{~b} / \mathrm{v})$ for 24 hours, to adsorb lead. [Mullich et al., 2017] compared commercial adsorbents and rice husk to remove chromium (VI) in artificial waste at contact time of 300 minutes. The result of adsorption capacity with commercial adsorbent was $43.79 \mathrm{mg} / \mathrm{g}$, while with rice husk the adsorption capacity of $34.85 \mathrm{mg} / \mathrm{g}$ was obtained. [El-Shafey, 2010] studied husk charcoal that was activated with $13 \mathrm{M}$ sulfuric acid to remove zinc and mercury. The optimum conditions were obtained at $\mathrm{pH} 6$, the concentration of adsorbate $50 \mathrm{mg} / \mathrm{L}$, and the adsorbent mass of $0.1 \mathrm{~g}$.

Several factors that influence the adsorption processes include the properties of adsorbent, adsorbate concentration, adsorption properties, temperature, $\mathrm{pH}$, and contact time. In addition, there is an activation process of adsorbent which is an adsorbent modification to increase the capacity and efficiency of adsorption. Activation can be performed by chemical treatments as reacted with acids or bases and physical treatments such as heating and washing [Marshall and Johns, 1996].

The most widely used adsorption models in the analysis of experimental adsorption data are Freundlich isotherm and Langmuir isotherm [ElMoselhy et al., 2017; Banerjee et al., 2016; Bhatti et al., 2015]. The Freundlich isotherm model is widely used in the adsorption process in drinking water and wastewater [Reynold and Richard, 1996] with the assumption that the adsorption occurs physically. The Freundlich isotherm model is able to describe the adsorption of organic and inorganic compounds over a wide range for various adsorbents. The Freundlich isotherm model is expressed as the follow equation:

$$
\frac{x}{m}=K C e^{1 / n}
$$

where: $x / m$ is mass of adsorbate per mass of adsorbent (is called adsorption capacity, expressed in $\mathrm{mg} / \mathrm{g}$ ),

$K$ and $n$ are Freundlich constant (dimensionless), and

$\mathrm{Ce}$ is the adsorbate concentration at equilibrium in $\mathrm{mg} / \mathrm{L}$.

The Langmuir isotherm model assumes that the amount of surface site which adsorb the absorbent is fixed, in accordance with the surface area of the adsorbent and is reversible. Equilibrium is achieved when the adsorption speed of the molecule to the surface of the adsorbent is equal to the speed of molecular desorption of the adsorbent surface. The Langmuir isotherm model is expressed as the follow equation:

$$
\frac{x}{m}=\frac{q m b c_{x}}{1+b c_{x}}
$$

where: $q m$ and $b$ are Langmuir constant (dimensionless), and

$\mathrm{Ce}$ is adsorbate concentration at equilibrium in $\mathrm{mg} / \mathrm{l}$.

The adsorption process can take place quickly or slowly, depending on many factors. The speed of the adsorption process is assessed in terms of the adsorption kinetics. According to [Hammed and Ahmad, 2010], a model widely used in the study of adsorption kinetics is pseudo first order kinetics and pseudo-second order kinetics. The pseudo-first order kinetics equation is expressed by equation (3) and the pseudo-second order adsorption kinetics is expressed by equation (4) [Fang et al., 2018].

$$
\begin{gathered}
\log (q e-q t)=q e-\frac{K_{1}}{2,303} t \\
\frac{t}{q t}=\frac{1}{K_{2} q_{s}{ }^{2}}+\frac{1}{q_{s}} t
\end{gathered}
$$

where: qe is the metal ion adsorption capacity at equilibrium $(\mathrm{mg} / \mathrm{g})$,

$q t$ is the amount of ion absorbed at time $\mathrm{t}$ (mg/g),

$K_{1}$ is the pseudo-first order kinetics constant $\left(\mathrm{min}^{-1}\right)$, and

$K_{2}$ is the pseudo-second order kinetics constant ( $\left.\mathrm{mg} / \mathrm{g} \mathrm{min}{ }^{-1}\right)$. 


\section{MATERIALS AND METHODS}

\section{Preparation of Rice Husk Adsorbent}

The production of rice husk adsorbents begins with washing to remove impurities, then drying in an oven for 3 hours at $110^{\circ} \mathrm{C}$ to reduce the water content [Hsu et al., 2009]. After drying, the rice husk is then burned in the furnace for 2 hours at a temperature of $400^{\circ} \mathrm{C}$ until it becomes charcoal. In this process the combustion is maintained so that no air enters so the rice husk does not burn to ash. The next process is activation by immersion of $5 \% \mathrm{HCl}(\mathrm{v} / \mathrm{v})$ on the carbon to acid ratio of $1: 10(\mathrm{w} / \mathrm{v})$ for 24 hours [Hanum et al., 2017]. The adsorbent of the husk is sieved to obtain the size according to the variation of media size used, i.e. $2.0-0.841 \mathrm{~mm}$ (10-20 mesh) and 0.4-0.29 mm (40-50 mesh).

\section{Adsorbent Characterization with SEM-EDX}

Prior to use in the adsorption process, the adsorbent was characterized by Scanning Electron Microscopy-Energy Dispersive X-ray (SEM-EDX). The characterization of the adsorbent aims at finding out the content of the adsorbent material and the grain surface image as well as the pore distribution of the adsorbent based on particle size and the type of adsorbent.

\section{Precipitation Experiment}

The precipitation process was carried out by adjusting the $\mathrm{pH}$. The $\mathrm{pH}$ variations are 7 , 8,9 , and 10 (as the minimum metal solubility). The chemical used to raise the $\mathrm{pH}$ was $\mathrm{NaOH}$ $50 \%$. During precipitation, stirring was done at $120 \mathrm{rpm}$ for one minute to obtain the homogeneous mixture. Then, it was followed by slow stirring at $45 \mathrm{rpm}$ for 20 minutes. After the slow stirring was complete, the waste sample was clarified for 5 hours to obtain the most precipitation. The supernatant was filtered, and filtrate was measured by AAS (Atomic Absorption Spectrometry) method according to the American Public Health Association (APHA).

\section{Isotherm Adsorption Experiment}

The adsorption isotherm experiments were conducted in batch with variations of adsorbent size. The added adsorbent mass was $0.5 \mathrm{~g}$, $1.0 \mathrm{~g}, 1.5 \mathrm{~g}, 2.0 \mathrm{~g}$ [Alexander et al., 2017]. The experiment was carried out by putting $100 \mathrm{ml}$ of sample into the flask and then adsorbent was added according to the specified variation. Then, the mixture of the sample and adsorbent was stirred at $150 \mathrm{rpm}$ [Alexander et al., 2017] for 3 hours and the sample was subsequently filtered with filter paper. The filtered sample was analyzed for each metal concentration by AAS method.

\section{RESULTS AND DISCUSSION}

\section{Wastewater Characteristics}

The wastewater samples used in the experiments included the jewellery industry wastewater from Surabaya, Indonesia. The wastewater characteristics can be seen in Table 1. The large concentration of $\mathrm{Cu}$ is caused by the use of acid solutions in the process of producing gold jewellery.

\section{Adsorbent Profile of Rice Husk Charcoal with SEM-EDX}

Before being used as adsorbent, the rice husk charcoal was analyzed with SEM-EDX method to know the surface description and composition of adsorbent. The characteristic of rice husk before being used as adsorbent can be seen in Figures 1 to 7 .

The rice husk charcoal before activation (Figure 2) shows that some of the pores present in the carbon are still covered by hydrocarbons and other organic compounds. These carbon components include bonded carbon, ash, water and nitrogen. The activation process results in a larger carbon surface area due to the breaking of hydrocarbon bonds or the oxidation process of the surface molecules that clog pores. The activation process also increases the silica content. The EDX spectra result of rice husk charcoal characterization before and after activation showed a significant difference. The percentage of silica before activation is $8.45 \%$, while after activation, it increased to $19.41 \%$. The rice husk adsorbent with particle size of 10-20 mesh and 40-50 mesh

Table 1. Characteristics of Wastewater Samples

\begin{tabular}{|c|c|c|c|}
\hline Parameters & Unit & Value & Standard* $^{*}$ \\
\hline $\mathrm{Cu}$ & $\mathrm{mg} / \mathrm{L}$ & 3,227 & 2 \\
\hline $\mathrm{pH}$ & - & $0,6-0,7$ & $6-9$ \\
\hline
\end{tabular}

*) Effluent standard according to the local governmental regulation 
a)

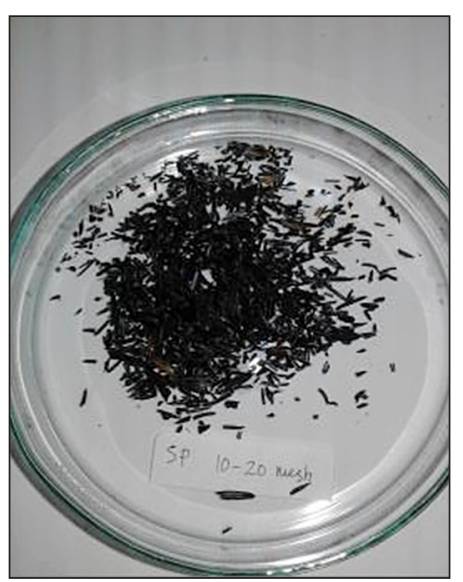

b)

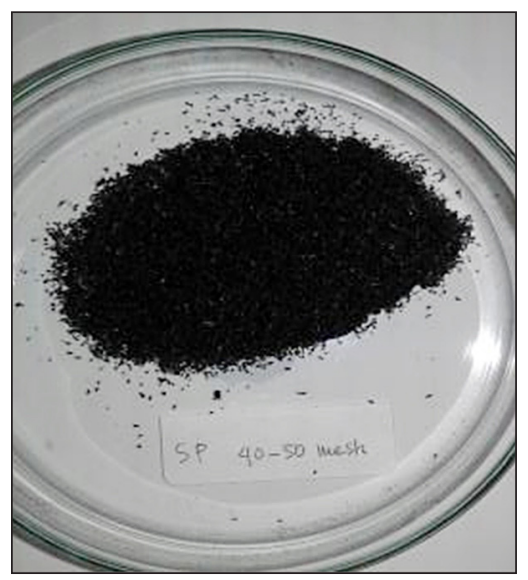

Figure 1. Photo of rice husk charcoal: a) particle size 10-20 mesh; b) particle size 40-50 mesh

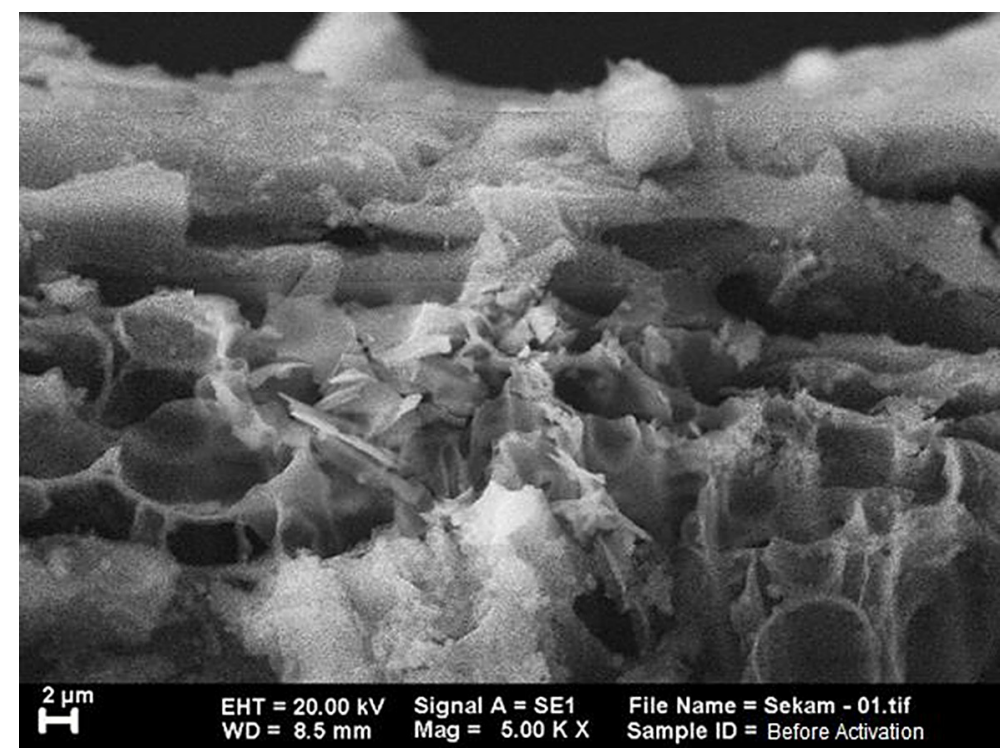

Figure 2. SEM micrograph of rice husk charcoal before activation at 5000x magnification

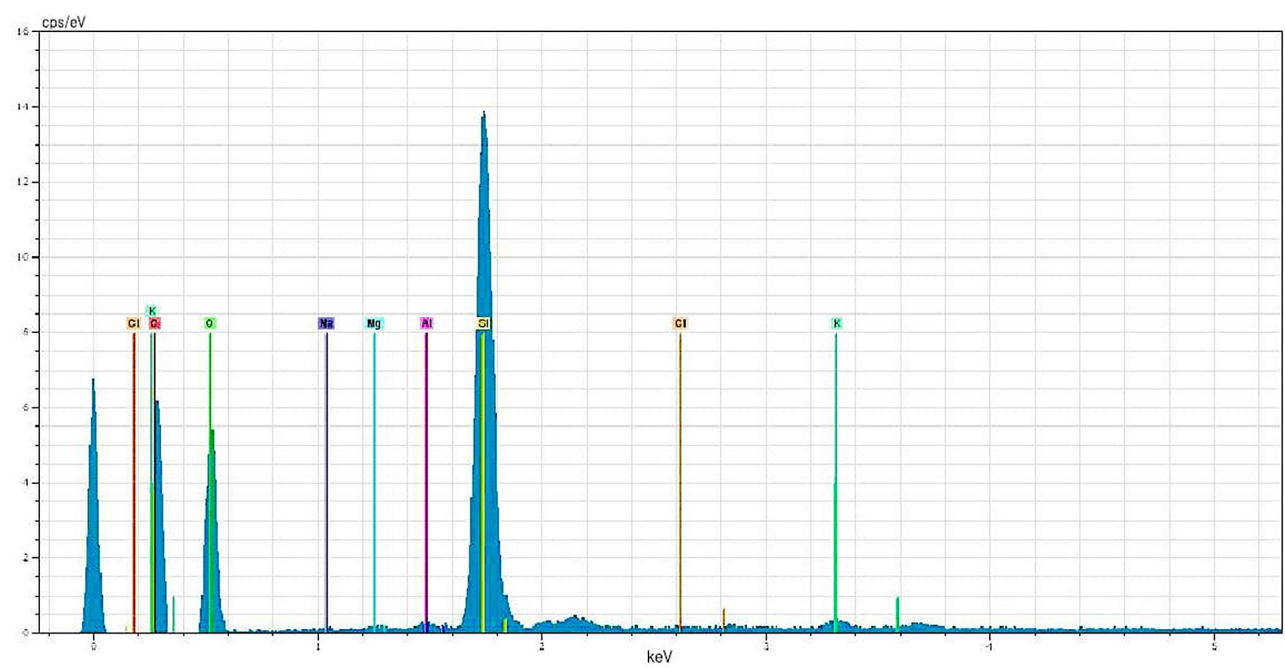

Figure 3. EDX spectra of rice husk charcoal before activation 


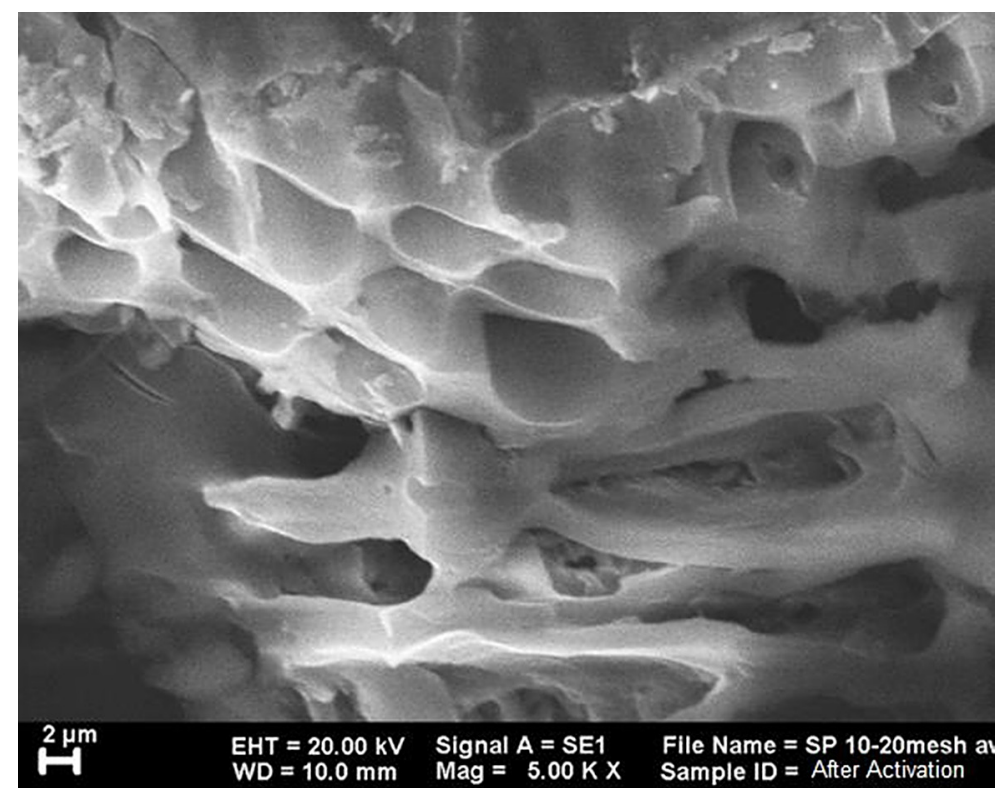

Figure 4. SEM micrograph of rice husk charcoal of 10-20 mesh after activation at 5000x

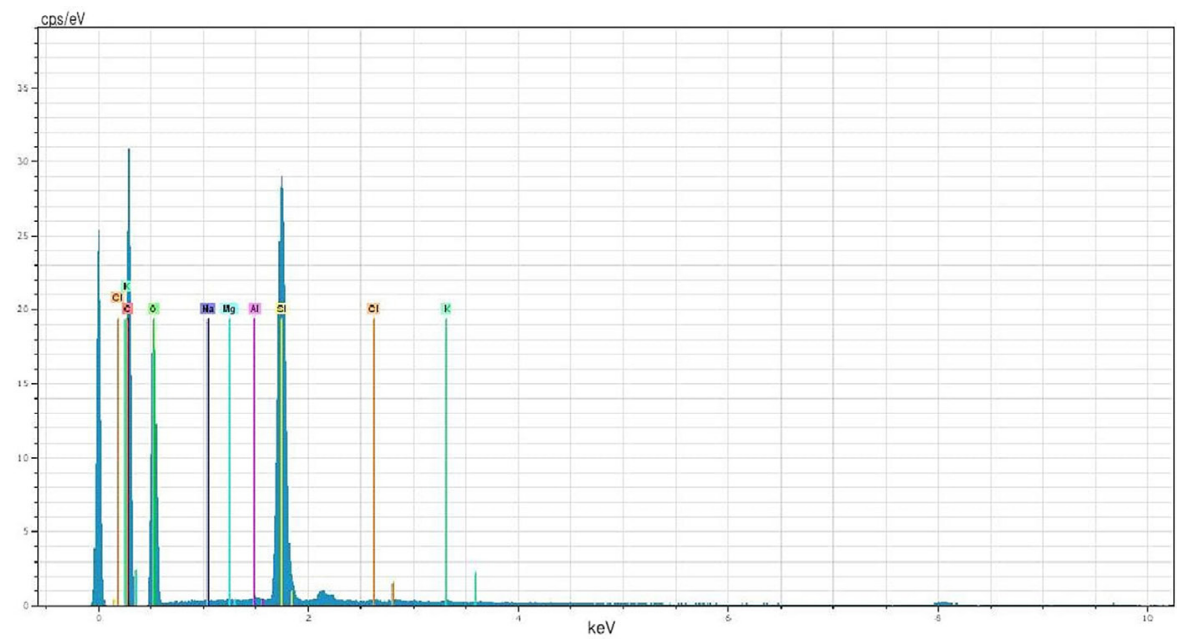

Figure 5. EDX spectra of rice husk charcoal of 10-20 mesh after activation

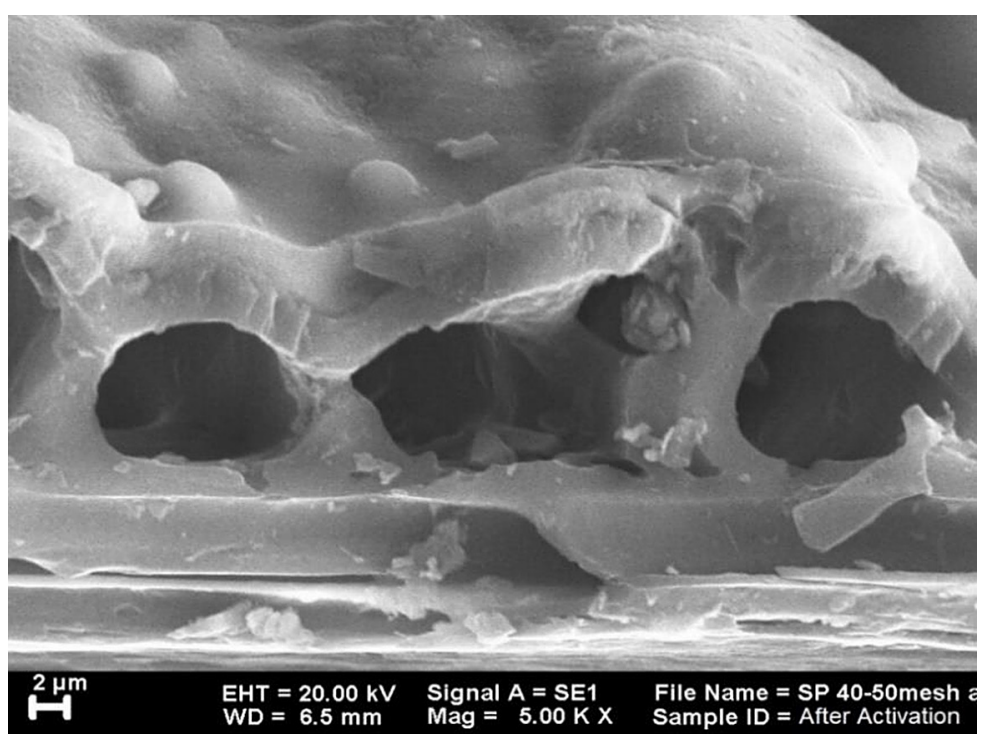

Figure 6. SEM micrograph of rice husk charcoal of 40-50 mesh after activation at 5000x 


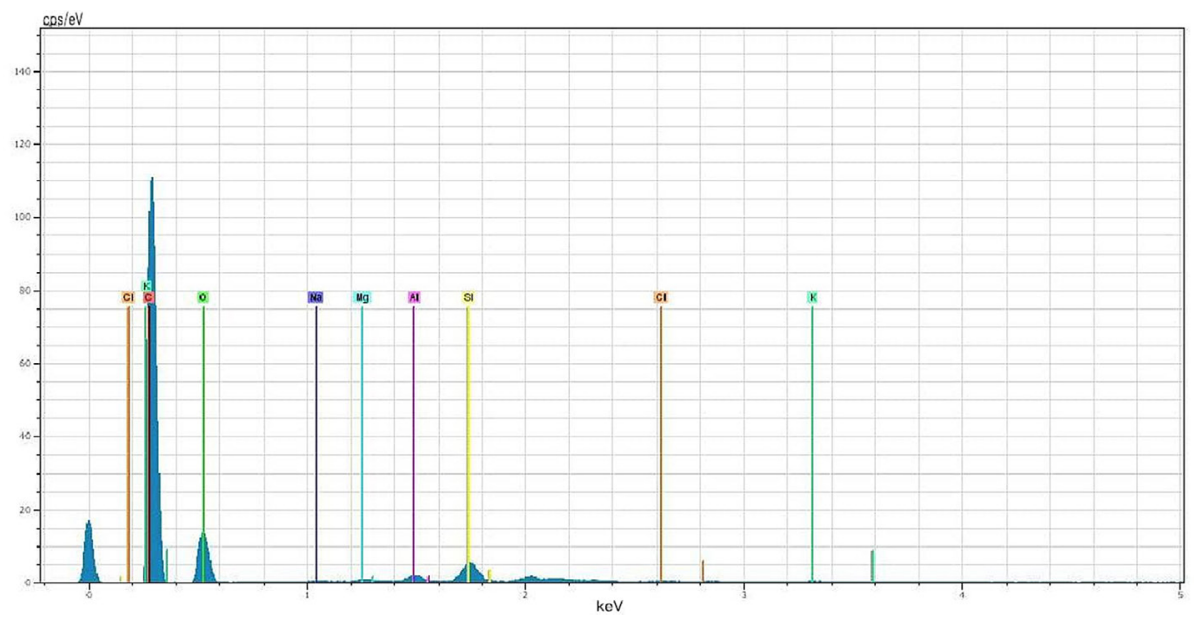

Figure 7. EDX spectra of rice husk charcoal of 40-50 mesh after activation

show pore or empty hollow and arranged regularly. This pore will become the adsorption site in the adsorption process.

\section{Preliminary Experiment}

Before the adsorption experiments were performed, the wastewater samples were precipitated by the addition of sodium hydroxide to increase the $\mathrm{pH}$ value and followed by precipitate formation. The process of precipitation of the waste sample was carried out as a preliminary study to reduce the metal content by adding $\mathrm{NaOH}$ as a precipitating agent. In this case, it is expected to form a lot of hydroxide metal solids that can be physically separated. Precipitation was performed at $\mathrm{pH} \mathrm{7,8,9}$ and 10 variations. The addition of $\mathrm{NaOH}$ to the waste sample was proportional to the increase in $\mathrm{pH}$ of wastewater due to the presence of $\mathrm{OH}$ ions derived from the addition of $\mathrm{NaOH}$. This ion reacts with the metal cations in the waste sample to form a precipitate of the hydroxide metal as the reaction follows.

$$
\begin{gathered}
\mathrm{NaOH} \rightarrow \mathrm{Na}^{+}+\mathrm{OH}^{-} \\
2 \mathrm{OH}^{-}+\mathrm{Cu}^{2+} \leftrightarrow \mathrm{Cu}(\mathrm{OH})_{2(\mathrm{~s})}
\end{gathered}
$$

In this study, the process of precipitate formation after the addition of $\mathrm{NaOH}$ was very rapid. In the precipitation process, there was a separation between the supernatant and the precipitate. The copper metal content of the supernatant was measured. The result of measurement data with AAS related to the effect of $\mathrm{pH}$ on copper metal concentration can be seen in Figure 8.

At $\mathrm{pH}$ 9, the precipitation process is most optimal and can reduce the copper content by $99 \%$. This corresponds to the metal solubility curve, i.e. pH 9 is the minimum solubility point for the copper metal. A perfect precipitation process occurs at $\mathrm{pH} 9$, but it requires a lot of $\mathrm{NaOH}$ solution in the formation of a hydroxide metal solid. The

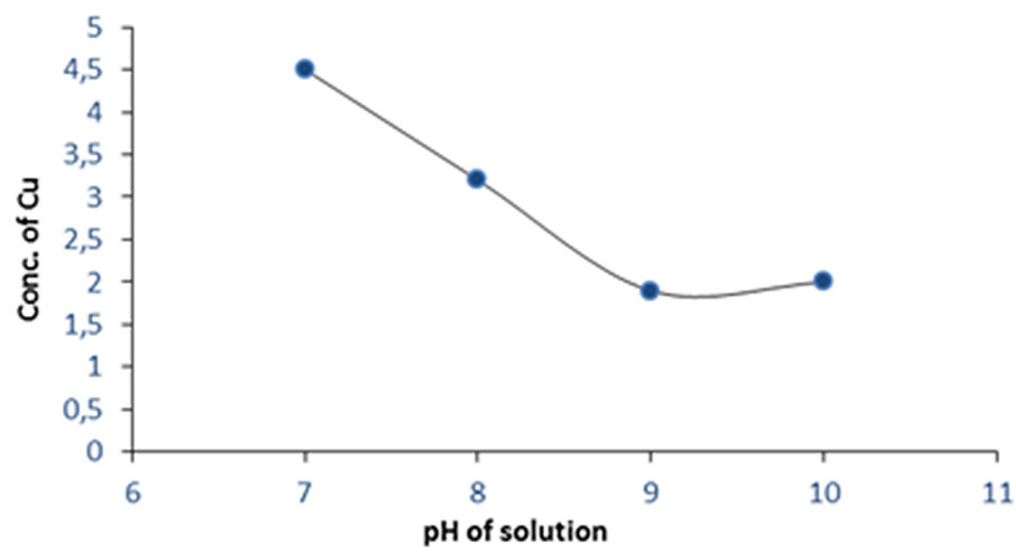

Figure 8. Graph of effect of $\mathrm{pH}$ on copper concentration on supernatant after precipitation process 
precipitation process at $\mathrm{pH} 7$ (neutral condition) is considered capable of significantly decreasing the copper metal content by $99.86 \%$. The result of waste precipitation at $\mathrm{pH} 7$ indicates that the copper content still does not meet the quality standard (max $2 \mathrm{mg} / \mathrm{L}$ ). Therefore, further treatment is required with the adsorption process to reduce the copper content.

\section{Adsorption Experiment}

The adsorption process of the precipitated sample was carried out using the physically-activated rice husk charcoal. The particle size variation of adsorbent was 10-20 mesh and 40-50 mesh. The batch adsorption process was done by varying the adsorbent mass and contact time.

\section{Effect of Adsorbent Size and Mass}

The adsorption of copper metal was carried out at an initial copper concentration of $1.9 \mathrm{mg} / \mathrm{L}$. The rice husk charcoal as used adsorbent had two kinds of grain size, which is 10-20 mesh and 40-50 mesh. The adsorbent mass was varied with $0.5,1.0,1.5$, and 2.0 grams. After contact between the wastewater with the adsorbent in a certain time, the sample was filtered, and the filtrate was analyzed with AAS. The concentration of copper in the sample can be seen in Table 2 .

Table 2 shows that two grams mass of adsorbent mass obtained the largest adsorbate (copper) mass compared to the others. Meanwhile, the 10-20 mesh adsorbent size adsorbs much more copper than the 40-50 mesh adsorbent. In general, the magnitude of the adsorption capacity increases with the amount of adsorbent mass. The ability to absorb metal ions also increases along with the initial concentration of metal ions.

Observing the results of this experiment, the adsorption is relatively low. This is because the initial concentration of copper is low as well. The greater the concentration is, the higher the number of molecules in the solution; thus, the interaction between adsorbate molecules and adsorbents

Table 2. Metal Concentration (mg/L $\mathrm{Cu})$ after Adsorption Process

\begin{tabular}{|c|c|c|c|c|}
\hline \multirow{2}{*}{$\begin{array}{c}\text { Adsorbent size } \\
\text { (mesh) }\end{array}$} & \multicolumn{4}{|c|}{ Mass of Adsorbent (g) } \\
\cline { 2 - 5 } & 0.5 & 1.0 & 1.5 & 2.0 \\
\cline { 2 - 5 } & \multicolumn{4}{|c|}{ Concentration of Cu (mg/L) } \\
\hline $10-20$ & 1.82 & 1.74 & 1.68 & 1.58 \\
\hline $40-50$ & 1.87 & 1.84 & 1.76 & 1.58 \\
\hline
\end{tabular}

is increased. In addition, this low absorption rate was due to the presence of noncarbon compounds such as ash, water and other metals attached to the surface of activated carbon, which covered the pores [Sathasivam and Haris, 2010].

\section{Influence of Contact Time}

The adsorption process by varying the contact time was carried out to test the effect of contact time or the chance of interaction between the adsorbate and the adsorbent. After the specified time $(0.5,1,2$, and 4 hours $)$, the sample was filtered, and the filtrate was analyzed by AAS. The concentration of copper in the sample can be seen in Table 3.

Table 3 shows that the removal of copper metal by rice husk charcoal increases along with the contact time. This indicates that with the increase of contact time, the chance of interaction between adsorbate and adsorbent is longer, so that the absorption process increases and the remaining metal content in the solution becomes reduced. The optimum contact time in copper metal removal is 4 hours (240 minutes). This result similar to the one reported by [El-Moselhy et al., 2017], i.e. the highest removal of copper and cadmium metals in a solution with rice husk adsorbents also occurred at the longest contact time of 120 minutes.

\section{Adsorption Model}

Laboratory experimental data were analyzed by the Freundlich and Langmuir isotherm adsorption model as expressed in equation (1) and equation (2). The data analysis obtained Freundlich and Langmuir constants, as can be seen in Table 4.

An adsorption experiment with variation of adsorbent size showed that 40-50 mesh adsorbent size resulted in a larger adsorption capacity than adsorption with 10-20 mesh adsorbent. Thus, the copper metal adsorption process with 40-50 mesh rice husk adsorbents tends to follow Freundlich isotherm model with $\mathrm{R}^{2}$ value of 0.9625 . This explains that the process of adsorption of copper with rice husks is multilayer and

Table 3. Metal Concentration $(\mathrm{mg} / \mathrm{L} \mathrm{Cu})$ after Adsorption Process based on Variations of Contact Time

\begin{tabular}{|c|c|c|c|c|}
\hline \multirow{2}{*}{$\begin{array}{c}\text { Adsorbent size } \\
\text { (mesh) }\end{array}$} & \multicolumn{4}{|c|}{ Contact Time (hours) } \\
\cline { 2 - 5 } & 0.5 & 1 & 2 & 4 \\
\hline & \multicolumn{4}{|c|}{ Concentration of Cu (mg/L) } \\
\hline $10-20$ & 1.15 & 0.81 & 0.63 & 0.44 \\
\hline $40-50$ & 0.92 & 0.72 & 0.45 & 0.32 \\
\hline
\end{tabular}


Table 4. Results of Copper Adsorption Isotherms using Rice Husk Charcoal

\begin{tabular}{|c|c|c|c|c|c|c|}
\hline \multirow{2}{*}{$\begin{array}{c}\text { Adsorbent size } \\
\text { (mesh) }\end{array}$} & \multicolumn{3}{|c|}{ Freundlich } & \multicolumn{3}{c|}{ Langmuir } \\
\cline { 2 - 7 } & $\mathrm{n}$ & $\mathrm{K}$ & $\mathrm{R}^{2}$ & $\mathrm{~b}$ & $\mathrm{q}_{\mathrm{m}}$ & $\mathrm{R}^{2}$ \\
\hline $10-20$ & 4.2955 & 0.0138 & 0.0842 & 2.045 & 0.0201 & 0.075 \\
\hline $40-50$ & -0.1574 & 0.3035 & 0.9625 & -0.678 & 0.0012 & 0.8957 \\
\hline
\end{tabular}

rather ignores the effect of surface area, where the 10-20 mesh adsorbent should theoretically result in a larger adsorption capacity.

\section{SEM-EDX Analysis of Adsorbent after Adsorption}

The SEM-EDX analysis after the adsorption process was performed to characterize the surface features of the rice husk charcoal and prove the metal attachment on the surface of the adsorbent. The result of characterization with SEM-EDX can be seen in Figures 9 and 10.
There is the adsorbate membrane attached on the surface of adsorbent that was used in the process of metal adsorption, so the pores of the adsorbent become slightly closed. At 5.000× magnification, it appears that the pores of the adsorbent are already covered by adsorbate adsorbed on the surface of adsorbent. The existence of these pores explains that the adsorption process that occurs in this research is multilayer adsorption. Figure 10 shows that the rice husk charcoal used in the adsorption process

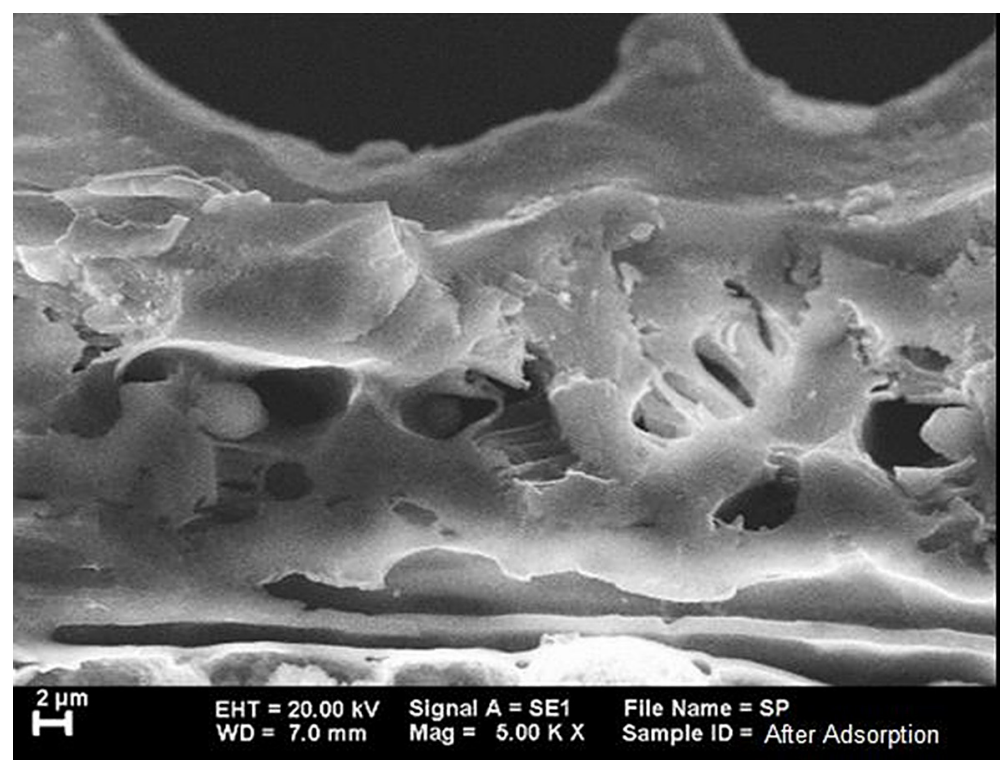

Figure 9. SEM micrograph of rice husk charcoal of 40-50 mesh after adsorption process

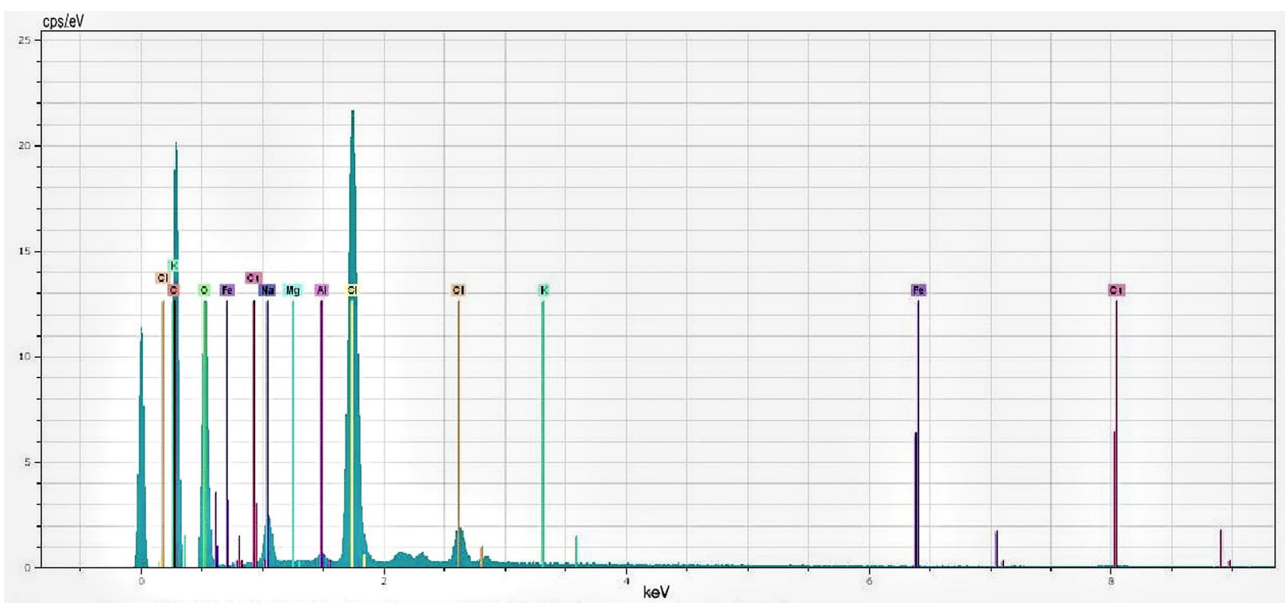

Figure 10. EDX spectra of rice husk charcoal after used in adsorption process 
Table 5. Composition of rice husk charcoal

\begin{tabular}{|c|c|}
\hline Element & Weight (\%) \\
\hline Carbon $(\mathrm{C})$ & 28.01 \\
\hline Oxygen $(\mathrm{O})$ & 48.18 \\
\hline Natrium $(\mathrm{Na})$ & 3.54 \\
\hline Chlor $(\mathrm{Cl})$ & 2.16 \\
\hline Copper $(\mathrm{Cu})$ & 1.07 \\
\hline Potassium $(\mathrm{K})$ & 0.11 \\
\hline Magnesium $(\mathrm{Mg})$ & 0.07 \\
\hline Iron $(\mathrm{Fe})$ & 0.23 \\
\hline Silicon $(\mathrm{Si})$ & 16.40 \\
\hline
\end{tabular}

absorbed the copper metal. It can be seen from the EDX data that contained elements of copper $(\mathrm{Cu})$. The chemical content composition of the adsorbent used is shown in Table 5. After the adsorption process, there were $\mathrm{Cu}$ elements of $1.07 \%$. This shows that the adsorbent of rice husk absorbed $\mathrm{Cu}$.

\section{CONCLUSIONS}

The treatment of jewellery waste water with a very high copper metal content begins with precipitation process. By adjusting the $\mathrm{pH}$ to alkaline conditions, the copper is easily precipitated. After the copper concentration reaches a lower value, the next process is adsorption with rice husk. The copper content in the jewellery wastewater can be adsorbed with a 40-50 mesh rice husk charcoal and the adsorption process follows the Freundlich isotherm model with $\mathrm{R}^{2}$ value of 0.9625 .

\section{Acknowledgements}

Acknowledgements and appreciations are given to LPDP (Institute of Education Fund Management), Ministry of Finance of the Republic of Indonesia which has provided education and research funds, so this research can be well done.

\section{REFERENCES}

1. Ahmad, A.A. and Hameed, B.H. 2010. Fixed-Bed Adsorption of Reactive Azo Dye onto Granular Activated Carbon Prepared from Waste. Journal of Hazardous Materials, 175(1-3): 298-303. doi: 10.1016/j.jhazmat.2009.10.003

2. Alexander, D., Ellerby, R., Hernandez, A., Wu, F. and Amarasiriwardena, D. 2017. Investigation of Simultaneous Adsorption Properties of $\mathrm{Cd}, \mathrm{Cu}$,
$\mathrm{Pb}$ and $\mathrm{Zn}$ by Pristine Rice Husks using ICP-AES and LA-ICP-MS Analysis. Microchemical Journal, 135, 129-139. doi: 10.1016/j.microc.2017.08.001

3. Asuquo, E.D., Martin, A.D, Nzerem, P., Siperstein, F. And Fan, X. 2017. Adsorption of Cd(II) and $\mathrm{Pb}$ (II) Ions from Aqueous Solutions Using Mesoporous Activated Carbon Adsorbent: Equilibrium, Kinetics and Characterization Studies. Journal of Environmental Chemical Engineering, 5(1): 679-698. doi: 10.1016/j.jece.2016.12.043

4. Azimi, A., Azari, A., Rezakazemi, M. and Ansarpour, M.. 2017. Removal of Heavy Metals from Industrial Wastewaters: A Review, Chem. Bio. Eng, 4(1): 37-59. doi: 10.1002/cben.201600010

5. Banerjee, A., Mukherjee, S., LaminKa-ot, A., Joshi, S.R., Mandal, T. and Halder G. 2016. Biosorptive Uptake of $\mathrm{Fe}^{2+}, \mathrm{Cu}^{2+}$ and $\mathrm{As}^{5+}$ by Activated Biochar Derived from Colocasia esculenta: Isotherm, Kinetics, Thermodynamics, and Cost Estimation. Journal of Advanced Research, 7(5): 597-610. doi: 10.1016/j.jare.2016.06.002

6. Bhatti Z.A., Maqbool F., Qayyum S., Farooq J., Manzor R., Zhao Y.G., 2015, Characterization of Toxic Metals Adsorption Isotherms on Activated Carbon using Locally Design Jar Test Apparatus. Science, Technology and Development, 2(34): 109-113. doi: 10.3923/std.2015.109.113

7. El-Moselhy, K.M., Abdel-Azzem, M., Amer, A. and Al-Prol, A.E. 2017. Adsorption of $\mathrm{Cu}(\mathrm{II})$ and Cd(II) from Aqueous Solution by Using Rice Husk Adsorbent. Physical Chemistry: An Indian Journal, 12(2): 109.

8. El-Shafey, E.I. 2010. Removal of $\mathrm{Zn}$ (II) and $\mathrm{Hg}$ (II) from Aqueous Solution on a Carbonaceous Sorbent Chemically Prepared from Rice Husk. Journal of Hazardous Materials, 175(1-3): 319-327. doi: 10.1016/j.jhazmat.2009.10.006

9. Fang, L., Li, L., Qu, Z., Zu, H., Xu, J. and Yan, N. 2018. A Novel Method for the Sequential Removal and Separation of Multiple Heavy Metals from Wastewater. Journal of Hazardous Materials, 342: 617-624. doi: 10.1016/j.jhazmat.2017.08.072

10. Hanum, F., Bani, O. and Wirani, L.I. 2017. Characterization of Activated Carbon from Rice Husk by $\mathrm{HCl}$ Activation and Its Application for Lead (Pb) Removal in Car Battery Wastewater. IOP Conference Series: Materials Science and Engineering, 180012151.

11. Hsu, S.T., Chen, L.C., Lee, C.C., Pan, T.C., You, B.X. and Yan, Q.F. 2009. Preparation of Methacrylic Acidmodified Rice Husk Improved by an Experimental Design and Application for Paraquat Adsorption. Journal of Hazardous Materials, 171(1-3): 465-470. doi: 10.1016/j. jhazmat.2009.06.144

12. Karniba, M., Kabbanib, A., Holaila, H. and Ola- 
maa, Z. 2014. Heavy Metals Removal using Activated Carbon, Silica and Silica Activated Carbon Composite. Energy Procedia, 50(2014): 113-120. doi: 10.1016/j.egypro.2014.06.014

13. Lata, S. and Samadder, S. 2014. Removal of Heavy Metals using Rice Husk: A Review. International Journal of Environmental Research and Development, 4(2): 165-170.

14. Marshall, W.E. and Johns, M.M. 1996. Agriculture by-product as Metal Adsorbent: Sorption Properties and Resistance to Mechanical Abrasion. J. Chem Tech Biotechnology, 66(3): 192-198. doi: 10.1002/(SICI)1097-4660(199606)66:2<192::A ID-JCTB489>3.0.CO;2-C

15. Mullick, A., Siddhartha, M. and Sangita,,B. 2017. Removal of Hexavalent Chromium from Aqueous Solutions by Low-Cost Rice Husk-Based Activated Carbon: Kinetic and Thermodynamic Studies. Indian Chemical Engineer, 60(1): 58-71. doi: 10.1080/00194506.2017.1288173

16. Noor, N.M., Raihan, O., Mubarak, M.N. and Abdullah, E.C. 2017. Agricultural Biomass-Derived Magnetic Adsorbent: Preparation and Application for Heavy Metals Removal. Journal of the
Taiwan Institute of Chemical Engineers, 78(2017): 168-177. doi: 10.1016/j.jtice.2017.05.023

17. Rahman, M.M., Awang, M., Mohosina, B.S., Kamaruzzaman, B.Y., Nil, W.B. and Adnan, C.M. 2012. Waste Palm Shell Converted to High Efficient Activated Carbon by Chemical Activation Method and its Adsorption Capacity Tested by Water Filtration. APCBEE Procedia, 1(2): 293-298. doi: 10.1016/j.apcbee.2012.03.048

18. Reynold, T.D. and Richard P.A. 1996. Unit Operations and Processes in Environmental Engineering, Second Edition, PWS Publishing Company, USA.

19. Sathasivam, K. and Haris, M.R.H.M. 2010. Banana Trunk Fibers as An Efficient Biosorbent for the Removal of $\mathrm{Cd}, \mathrm{Cu}, \mathrm{Fe}$, and $\mathrm{Zn}$ from Aqueous Solution. Journal of the Chilean Chemical Society, 55(2): 278-282. doi: 10.4067/ S0717-97072010000200030

20. Ye, H., Zhang, L., Zhang, B., Wu, G. and Du, D. 2012. Adsorptive Removal of $\mathrm{Cu}$ (II) from Aqueous Solution using Modified Rice Husk. International Journal of Engineering Research and Applications (IJERA), 2(2): 855-863. 